\title{
Over-nutrition in children and influence of parental attributes
}

\section{Pant S', Vaidya A ${ }^{2}$}

${ }^{1}$ Smriti Pant, Resident, ${ }^{2}$ Abhinav Vaidya, Professor, Kathmandu Medical College Public Limited, Kathmandu University, Kathmandu, Nepal

\begin{abstract}
Over-nutrition has presented itself as a significant public health issue in the past few decades. Its burden is increasing not only in developed countries, but also in developing countries. The objective of this review was to explore global and national burden of over-nutrition, its prevalence among children, and identification of the risk factors. It focused on assessing behavioral and socio-demographic attributes of parents that may influence obesity/overweight in children. For writing the literature review, national and international reports on over-nutrition, along with many journal articles on the related topic were reviewed. It showed that the burden of overweight/obesity has increased notably in the last three decades and is increasing more rapidly in developing countries.Moreover, it illustrated that its prevalence is high and has an increasing trend among children.Furthermore,the review also highlighted that parental attributes have an important influence on children's nutritional status. Thus given the important role that parents play in the nutrition of children, parents need to be a focus of the strategies to control the growing problem of over-nutrition among children.
\end{abstract}

Key words: Child; Obesity; Overweight; Parents; Prevalence

\section{INTRODUCTION}

$\mathrm{N}$ utritional status of individuals is an important marker of positive community health ${ }^{1}$. Malnutrition is a type of nutritional disorder with long lasting and serious consequences ${ }^{2}$, hence an important matter of public health concern. Although the word malnutrition is frequently used interchangeably with under-nutrition, in principle it also comprises of over-nutrition ${ }^{3}$. Undernutrition encompasses a spectrum of disorders from underweight (low weight for age), to stunting (low height for age), wasting (low weight for height) and lacking in vitamins and minerals (micronutrient malnutrition) ${ }^{3}$. On the other hand, over-nutrition is defined as an abnormal or excessive fat accumulation that may impair health, and it includes both overweight and obesity ${ }^{4}$. In order to determine the occurrence and severity of these nutritional disorders, various indicators are used. Among them, anthropometric indices are most commonly utilized ${ }^{5}$. These include Body Mass Index (BMI), Mid Upper Arm Circumference (MUAC), weight for age, height for age, weight for height etc ${ }^{5}$.

Address for correspondence

Dr. Smriti Pant

Resident

Department of Community Medicine

Kathmandu Medical College, Sinamangal, Kathmandu

E-mail: smritipant_2@hotmail.com
Till the late $20^{\text {th }}$ century, over-nutrition was more prevalent in developed countries and under-nutrition in developing countries. However recent estimates from World Health Organization (WHO) show that overnutrition has risen notably in developing countries as well ${ }^{4}$. As a result of this change, many countries now face the double burden of the disease 4 . Albeit under-nutrition still remains a major public health problem, especially in developing countries, over-nutrition has been coming to attention due to the increase in its prevalence and the fact that it is associated with an rise in morbidity and mortality ${ }^{4,6}$. Almost 3 million people worldwide die each year due to consequences of overweight or obesity, and it contributes largely to the Disability Adjusted Life Years $(D A L Y s)^{6}$. An over-nourished person has an increased risk of suffering from cancer of the breast, colon/rectum, endometrium, kidney, adenocarcinoma of oesophagus and pancreas ${ }^{7}$.

For over-nourished children, the health outcomes are even worse than adults. It increases their chances of acquiring certain non-communicable diseases (NCDs) such as insulin resistance and heart disease early in life ${ }^{8}$. As overweight/obese children are likely to retain their status as adults ${ }^{9}$, they also have the possibility of getting many ailments when they are older. An estimated 44 $\%$ of diabetes, $23 \%$ of ischemic heart disease, and 7 to 
$41 \%$ of cancer is attributed to be caused as a result of a being overweight or obese ${ }^{7}$. Suffice to say that being an overweight child leads to major health issues as adults.

Considering the evidence of the rise of obesity, World Health Assembly (WHA) endorsed a Global Strategy for the Prevention and Control (GSPC) of NCD $\sin 2000^{10}$. This commitment was strengthened further with the adoption of the strategy at the United Nation (UN) General Assembly on the Prevention and Control of NCDs in September $2011^{11}$. Nepal showed its support by signing this declaration ${ }^{12}$. It takes in account the fact that obesity is a multi-factorial disease, and has hence proposed a multi-sectoral strategy for its control and prevention. In Nepal, a Multi sectoral NCD Action Plan was developed in $2013^{12}$. This plan aims to reduce preventable morbidity, avoidable disability and premature mortality due to NCDs in Nepal. It includes targets of halting the rise in obesity and diabetes, reducing the prevalence of physical inactivity and others that are directly or indirectly related to prevention of over-nutrition ${ }^{12}$. Despite the plans to reduce the burden of over-nutrition, there is still an unintentional overlooking of the problem; with most of the government funds for improving nutritional status being utilized for prevention and control of under-nutrition. This has resulted in a slow decline in the number of undernourished children ${ }^{13,14}$; but rising numbers of over-nourished population ${ }^{13-16}$.

Prevention and control of over-nutrition is a difficult task because it is a multi-factorial disease and there are many variables that are incriminated as risk factors ${ }^{17}$. These include socio-demographic factors, environmental factors, genetic factors and behavioral factors ${ }^{17}$. Sociodemographic factors like educational level, income, occupation and employment status of parents ${ }^{18-24}$ and behavioral factors like eating habits and physical activities ${ }^{25-35}$; of both children and parents have been observed to play a major role in the nutritional status of children.

Even though over-nutrition is a preventable condition, lack of effectual policies and inadequate implementation of the existing policies has led to slow progression of the attempt to prevent and reduce its burden. This may be due to lack of adequate clinical evidence addressing these issues. Many developing countries do not have adequate studies representing national level data. Also not all studies assess causal factors. This has caused a scarcity of adequate information about the occurrence of over-nutrition and associated risk factors. Even the identified risk factors are yet to be considered while developing strategies for its control.This review aims to explore the global situation of malnutrition and it risks factors for over-nutrition with particular focus on parental attributes that affect occurrence of overnutrition in the children. It intends to study about the knowledge gaps in these areas.

\section{BODY}

This narrative review focuses on the global and national burden of over-nutrition, its prevalence among children, and identification of causative factors, focusing mainly on parental attributes. Hence the literature review has been divided accordingly. For writing this review, national and international reports on over-nutrition, along with many journal articles on the related topic were reviewed.

\section{GLOBAL BURDEN OF OVER-NUTRITION}

Obesity has been on the rise for the past few decades, and it was declared as an epidemic by WHO in $1997^{36}$. According to its estimation, the number of overweight people has increased by threefold since $1975^{4}$. In 2008, about 1.4 billion adults were overweight globally; that number increased to more than 1.9 billion in $2016^{4}$.The burden of over-nutrition among people has increased both in developed and developing countries 4 .

According to the obesity update in 2017, the United States of America (USA) and Mexico were the top two countries with the highest percentage of obese people among OECD (Organization for Economic Co-operation and Development) countries in 2015 ${ }^{37}$.Similarly, in England,about a quarter of men and similar percentage of women aged 16 years and more were obese in $2016^{38}$. Also, $40 \%$ and $30 \%$ of men and women respectively were found to be overweight in the same year ${ }^{38}$. Likewise, the prevalence of obesity among adult Australian population in 2014-15 was $28 \%$, which is almost one and half times rise from its value in $1995(19 \%)^{39}$.

The epidemic of obesity, which started in affluent countries, has successfully penetrated world's low income countries as well ${ }^{36,40}$. In China, there was a substantial rise in the prevalence of overweight and obesity in adults between 2004 and 2010: increasing from $25.9 \%$ in 2004 to $32 \cdot 3 \%$ in $2010^{40}$. The problem has continued to grow and in 2015, China was ranked second in the world according to the prevalence of obesity among adults ${ }^{41}$. Like China, the epidemic of overnutrition has spread to South Asian countries as well. It was estimated that $20.7 \%$ of the women and $18.9 \%$ men in India were either obese or overweight in 2015 -almost double from the 2005 figures $^{42}$. Likewise, the Pakistani Demography and Health Survey (PDHS) 2012-2013 
estimated that a quarter of women of reproductive age group were overweight and about $15 \%$ of them were obese $^{43}$.

\section{PREVALENCE OF OVER-NUTRITION AMONG CHILDREN}

With the rise in obesity worldwide, its prevalence among children has been increasing as well ${ }^{36,40,44}$.It was estimated that about 41 million children under the age of five and over 340 million children and adolescents aged 5-19 years were overweight or obese in $2016^{4}$. In United States of America(USA), the prevalence of obese children aged 6-11 years increased from $7 \%$ in 1980 to almost $18 \%$ in $2012^{45}$. Also, obesity was more prevalent among school-aged children and adolescents, when compared to preschool-aged children ${ }^{44}$. Similarly, in the United Kingdom (UK), 16\% of the children aged 2- 15 years were obese while $12 \%$ were only overweight but not obese ${ }^{38}$. In its neighboring country Denmark, the prevalence of children under 15 years of age who were either overweight or obese was $10 \%^{37}$. Similarly, in the Australian continent, almost 1 in 4 children were either overweight or obese in 2014-2015

The trends in malnutrition are changing, and now even developing countries have an increasing prevalence of over-nourished children ${ }^{47}$. According to $\mathrm{WHO}$, among all the under -five children who were overweight in 2016, majority lived in Asia (46\%) and Africa $(25 \%)^{47}$. Moreover, the number of overweight children (under 5 years of age) in Asia has risen considerably from 13.9 million in 2000 to 17.5 million in $2017^{47}$. Similarly in Africa, it has increased from 6.6 million in 2000 to 9.7 million in $2017^{47}$.

In 2015, China was ranked as the number one country in the world, according to number of obese children ${ }^{41}$, and India was ranked second ${ }^{41}$. In China, the number of overnourished children has increased noticeably in the last 3 decades $^{48}$. The percent of overweight and obese boys increased from 0.74 and 0.03 in 1985 to 16.4 and 17.2, respectively in $2014^{48}$. Similarly among girls, percentage of overweight and obese population increased from 1.5 and 0.12 in 1985 to 13.9 and 9.1, respectively in $2014^{48}$. Likewise, a systemic review of 52 studies conducted in 16 States of India between 2010-2013 showed a combined prevalence of childhood overweight and obesity to be $19.3 \%{ }^{49}$. In case of developing countries, it is seen that there is lack of nationally representative data with most of the research being done in sub-national populations. A study done in Dhaka, Bangladesh in 2015 to assess the prevalence of over-nutrition among 150 primary school children showed that the prevalence of childhood overweight and obesity was $52 \%$ and $20 \%$, respectively ${ }^{50}$.
Similarly, a cross-sectional study conducted among 501 students from high schools in Hyderabad city of Pakistan in 2009 illustrated that $12 \%$ of the students were obese and $8 \%$ were overweight ${ }^{51}$.

\section{BURDEN OF OVER-NUTRITION IN NEPAL}

Based on BMI, WHO STEPs survey 2007 estimated that about $7.2 \%$ of the population in Nepal, was either obese or overweight and approximately $1.7 \%$ was obese in $2007^{16}$. Similarly, WHO survey 2013 showed a rise in the numbers with about $17.7 \%$ of the population being overweight and four percent being obese ${ }^{15}$. Similarly, according to last two Nepal Demographic and Health Surveys (NDHS), the number of over-nourished women in Nepal has risen ${ }^{13,14}$. There was an increase in prevalence of overweight from $11 \%$ in the 2011 to $17 \%$ in the $2016^{13,14}$. Likewise, the prevalence of obesity has also risen slightly from two percent to five percent in the same duration ${ }^{13,14}$.

\section{PREVALENCE OF OVER-NUTRITION AMONG CHILDREN IN NEPAL}

In Nepal, research in the field of nutritional evaluation of children is mainly focused on assessment of undernutrition ${ }^{52-55}$. Nonetheless, several studies have been done in Nepal exploring over-nutrition as well ${ }^{56-61}$.A study in private schools of Lalitpur, Nepal reported that $14.5 \%$ children were obese and about $11 \%$ were overweight ${ }^{57}$. In the study, children belonging to upper class family, advantaged ethnic group, having two or less siblings, or who had large weight at birth had a higher odds of being overweight/obese $^{57}$. In contrast, a study done in Kaski, Nepal among 838 school going adolescents revealed lower prevalence of overweight (5.8\%) and obesity ( $2.3 \%$ ) among the children ${ }^{56}$. Another study that was carried out among 15-19 year olds at four different places of Nepal (Lalitpur, Thimi, Kushadevi and Dhulikhel) reported that out of the 324 children, three percent were overweight and less than one percent of them were obese. It also reported that socioeconomic status, sedentary lifestyle, father' BMI, mother's BMI were associated with overweight/obesity among children ${ }^{58}$. Likewise, a study conducted among 1900 students in Biratnagar, showed that $2.9 \%$ were overweight and $1.8 \%$ were obese $\mathrm{s}^{59}$. It also reported that studying in private schools and having a family income of more than ten thousand Nepalese rupees were strongly associated with overweight/obesity ${ }^{59}$. Contrary to these studies, a study done in a Sanskrit school in Baglung illustrated that no student was either obese or overweight ${ }^{60}$. However, many students were found to be undernourshied ${ }^{60}$. Another study among pre-school children in Bhaktapur 
showed that prevalence of overweight was $4.1 \%$. It also revealed that sedentary lifestyles of children and higher socio-economic status of the family was significantly related with overweight among children ${ }^{61}$.

Whilesome of these studies have reported only prevalence of over-nutrition, others have assessed only socio-demographic risk factors associated with over-nutrition. But, none of them review other causal elements like parental feeding preferences for their children, children's' feeding habit, physical activity of children and their parents, etc., which have been implicated as important risk factors for over-nutrition. Additionally, most of the studies are done at local/sub national level, so the data is not nationally representative and cannot be generalized. Even the surveys done by WHO and Nepal government are focused mainly on children under 5 years of age or individuals above 15 years of age and they report only prevalence. Thus, there is a wide knowledge gap regarding the prevalence of overweight/obesity among Nepalese children and causes related to it.

\section{RISK FACTORS FOR OVER-NUTRITION}

Over-weight and obesity are varying points in the spectrum of over-nutrition; hence they have similar risk factors. Even though all the causal factors may have not been identified completely, some factors are considered to be contributing to over-nutrition in children ${ }^{17}$. There has been a very rapid change in the number of obese children within a relatively stable population so there is an indication that genetic factors may not be the primary cause for the alteration ${ }^{62}$. However, genetic factors, environmental factors, lifestyle factors, education level, economy, and physical activity - all have been shown to play a fundamental role in the pathogenesis of overweight/obesity ${ }^{17}$. Moreover, in case of children, not only their own factors, but associated parental factors seem to play an important role in determining their nutrition status ${ }^{18-35}$.

\section{Effect of education level of parents}

Educational qualifications of the parents have been implicated as important risk factors that are inversely associated with obesity ${ }^{63}$. Higher the level of education of parents, there was lesser chance of off spring being overweight ${ }^{63}$. A study done in Lahore in 2005 illustrated that women's education was a very important underlying factor responsible for the nutritional status of children from low socioeconomic class. Similarly, higher education of mothers was related to better nutritional status of children ${ }^{24}$.

\section{Effect of employment status and occupation of parents}

Employment of parents plays an important role in the nutritional status of children ${ }^{18-21}$. Moreover, mothers' employment status have a greater impact on children's BMI than that of fathers' ${ }^{\prime 19,21}$. Additionally, not only employment status but other factors like duration of employment and whether both parents are employed at the same time, also effects BMI of children ${ }^{19-21}$.Prevalence of overweight is also seen to vary with occupation of parents, over-nutrition being more common among children with parents who have non-professional rather than professional jobs ${ }^{22}$.

\section{Effect of socio-economic status of parents}

There is evidence that economic status of the family affects BMI of children ${ }^{23,64}$. Those children who have parents with higher income have decreased risk of being overweight or obese ${ }^{64}$. Similarly, those children whose social status was low had three times more chance of being obese than children of the high social status ${ }^{23}$.

\section{Effect of physical activity}

Physical activity is another crucial element that decides whether or not a child becomes obese or overweight. In addition, physical activity and a person's ability to perform physical activity are chief modifiers of mortality and morbidity related to overweight and obesity ${ }^{65}$.

A study of children aged 10 to 13 years illustrated that,a decrease in participation in sports was associated with increased BMI ${ }^{25}$. Additionally, it was found that there was an inversely proportional relationship between moderate to vigorous physical activity and fat mass in 10 to 18 years old children ${ }^{26}$. Furthermore, lower BMI percentiles were seen in those children whose both parents were active ${ }^{27}$. Parent's activity also encouraged their off-springs to participate in organized sports ${ }^{27}$. Even though adequate physical activity has been proven to have many health benefits along with helping controlling weight gain ${ }^{65}$, some studies have shown that they do not have significant effect on $\mathrm{BMI}^{22,25,28}$.

\section{Effect of feeding habits}

Research has shown that eating habits and physical activity of an individual are strengthened early in life and are unlikely to change as they age ${ }^{66}$. So wrong habits formed during early childhood and adolescence may have a negative effect on nutritional status of individuals. This is supported by a study in China which concluded that high amount of fast food consumption by children and decreased physical activities among them are both very important factors for childhood obesity ${ }^{48}$. 
Furthermore, it is widely known that parents influence children's eating habit in many ways. Some parents make food choices for their children, while some act as role models for dietary preference, and yet other parents may use feeding practices to strengthen development of healthy eating patterns in their children ${ }^{67}$. There are various theories about benefits and drawbacks of restrictions practiced by parents in feeding their children $^{29-31}$. Studies demonstrate that parental constraints on restricted food-items increase their child's fondness for those foods, whilst forcing children to eat any food item was linked with reduction of preference for that food ${ }^{29}$. Other studies have also shown associations between 'controlling' feeding strategies and childhood over-nutrition ${ }^{30-31}$. Consequently, parents' feeding strategies may have important influence on children's eating patterns and weight ${ }^{31}$. But, parental control and regulation of children's eating habits may not always be counter productive and is likely to depend on how parents interact and communicate with their children on the topic $\mathrm{c}^{32,33}$. When children are encouraged to eat healthy foods, but also given some choices about eating options with parental explanation and rationales, higher intake of healthy food such as fruits and vegetables, and lower intake of energy-dense food can be achieved ${ }^{32,33}$.

\section{Effect of BMI of parents}

Parental BMI has also been related to the BMI of children. Several studies in Europe have shown that there is a directly proportional relationship between children's $\mathrm{BMI}$ and that of their parents ${ }^{34,35}$. Furthermore, some studies suggest that this association may be due to both genetic and environmental factors ${ }^{68}$. Studies also show that parents had limited ability to recognize that their child was overweight ${ }^{69}$.

\section{DISCUSSION AND CONCLUSION}

This review aimed to assess the global and national burden of over-nutrition, its prevalence among children, and identification of the risk factors, with a focus on behavioral and socio-demographic attributes of parents that may influence obesity/overweight in children. This review showed that overweight/obesity is increasing rapidly in most countries around the world, and the burden is surprisingly higher in the developing countries. This epidemic is notably spreading among children as well. Moreover, researches show that parental attributes have an important influence on children's nutritional status. However, the degree of influence may vary according to the different types of risk factors. Furthermore, as parents play an important role in the nutritional status of children, parents need to be one of the focus points while designing the strategies to control the growing problem of over-nutrition among children. Similarly, parents need to be educated about the importance of healthy eating habits and physical activities (of children as well as themselves) on the BMI of children and ultimately their health. Additionally, since children spend half of their time at school, the most feasible and effective approach to prevent over-nutrition would be to use preventive programs at schools.

\section{REFERENCES}

1. Park K. Park's textbook of preventive and social medicine. 23rd ed. India: Bhanot Publishers; 2015. Chapter 4: Concept of health and disease; p.26.

2. Factsheets: Malnutrition [Internet]. Geneva: World Health Organization; 2018[updated 2018 Feb 16; cited 2018 Aug 20]. [Website]

3. Progress for Children: A Report Card on Nutrition (No. 4) [Internet]. New York City (NY): United Nations Children's Fund; 2006 May[updated 2015 Jun; cited 2018 Apr 29]. Chapter 2: Nutrition: the foundation of survival and development; pg.2. [Website]

4. Factsheets: Obesity and overweight [Internet]. Geneva: World Health Organization; 2018[updated 2018 Feb 16; cited 2018 July 25]. [Website]

5. O'Donnell O, van Doorslaer E, Wagstaff A, Lindelow M. Analyzing Health Equity Using Household Survey Data: A Guide to Techniques and their

Implementation [Internet]. Washington: World Bank; 2007[cited 2018 Mar1]. Chapter 4: Health outcome \#2: anthropometrics.p.39-42. [DOI]

6. WHO. Global Health Observatory data on obesity: Situation and trends [Internet].Geneva: World Health Organization;2016[cited 2017 Oct 5]. [Website]

7. World Health Organization. Global health risks: mortality and burden of disease attributable to selected major risks [Internet]. Geneva: World Health Organization;2009[cited 2017 Oct 5]. 62 p. [Full Text]

8. WHO. Global Strategy on Diet, Physical Activity and Health : Why does childhood overweight and obesity matter? [Internet]. Geneva: World Health Organization;2018 [cited 2018 July 29]. [Website]

9. Simmonds M, Llewellyn A, Owen CG, Woolacott N. Predicting adult obesity from childhood obesity: A systematic review and meta-analysis. Obesity 
reviews[Internet]. 2016 Feb[cited 2017 Dec 8];17(2):95-107. [DOI]

10. Global strategy for the prevention and control of non-communicable diseases: Resolution (WHA 53.14) [Internet].Geneva: World Health Organization; 2000 Mar 22[cited 2017 Jan 10]. [Website]

11. United Nation General Assembly. Political declaration of the high-level meeting of the General Assembly on the prevention and control of noncommunicable diseases [Internet]. Geneva: World Health Organization; 2012 [cited 2017 Jan 15]. [Website]

12. Multisectoral action plan on the prevention and control of NCD in Nepal 2014-2020[Internet]. Kathmandu: Government of Nepal, World Health Organization; 2014 [cited 2017 Jan 15].[Website]

13. Ministry of Health and Population (NP), New ERA, and ICF International. Nepal demographic and health survey 2011 [Internet]. Kathmandu: Ministry of Health and Population (NP), New ERA, and ICF International; 2012[cited 2015 Sep 16]. Chapter 11: Nutrition of children and women;pg.163-68. [Full Text]

14. Ministry of Health and Population (NP), New ERA, and ICF International. Nepal demographic health survey 2016: key indicators report [Internet]. Kathmandu: Ministry of Health and Population (NP), New ERA, and ICF International; 2017[cited 2015 Sep 16]. Chapter 3:Key findings: child health and nutrition;pg.28-31. [Full Text]

15. Ministry of Health and Population (NP), Government of Nepal, Nepal Health Research Council, World Health Organization.Non Communicable Diseases Risk Factors: STEPS Survey Nepal 2013 [Internet]. Kathmandu: Ministry of Health and Population (NP), Government of Nepal, Nepal Health Research Council, World Health Organization. 2014[cited 2016 Dec 1].Chapter 11; Overweight and obesity;pg.38-9. [Full Text]

16. Ministry of Health and Population (NP), Government of Nepal, Nepal Health Research Council, World Health Organization. Non Communicable Diseases Risk Factors: STEPS Survey Nepal 2007/2008 [Internet]. Kathmandu: Ministry of Health and Population (NP), Government of Nepal, Nepal Health Research Council, World Health Organization. 2008[cited 2017 Dec 1]. Chapter 2: Results: physical measurements;.pg.66-7 [Full Text]

17. NHLBI:Overweightand obesity:riskfactors[Internet]. Bethesda (MD): National Heart, Lung, and Blood Institute;2018[cited 2018 Aug 18]. [Website]
18. Morrissey TW, Dunifon RE, Kalil A. Maternal employment, work schedules, and children's body mass index. Child Development[Internet]. 2011 Feb[cited 2018 Jan 17];82(1):66-81. [DOI]

19. Lee $S$, Young DR, Pratt CA, Jobe JB, Chae SE, McMurray RG, et al. Effects of Parents' Employment Status on Changes in Body Mass Index and Percent Body Fat in Adolescent Girls. Childhood Obesity[Internet]. 2012 Dec[cited 2017 Nov];8(6):526-32. [DOI]

20. Hope S, Pearce A, Whitehead M, Law C. Parental employment during early childhood and overweight at 7-years: findings from the UK Millennium Cohort Study. Bio Med Central Obesity [Internet]. 2015 Sep 16[cited 2017 Sep 17];2. [DOI]

21. Anderson PM, Butcher KF, Levine PB. The Economics of Obesity[Internet]. Washington(US):United States Department of Agriculture: Electronic publications from the food assistance \& nutrition research program; 2003 [cited 2017 May 7]. p14-17. [Full Text]

22. Strauss RS, Knight J. Influence of the home environment on the development of obesity in children. Pediatrics [Internet]. 1999[cited 2015 Dec 5];103(6):85-8.[PUBMED].

23. Lamerz A, Kuepper-Nybelen J, Wehle C, Bruning $\mathrm{N}$, Trost-Brinkhues $\mathrm{G}$, Brenner $\mathrm{H}$, et al. Social class, parental education, and obesity prevalence in a study of six-year-old children in Germany. International Journal of Obesity[Internet]. 2005 Mar 15[cited 2017 Jan 9];29(4):373-80. [DOI]

24. Brown KA, Ogden J, Vögele C, Gibson EL. The role of parental control practices in explaining children's diet and BMI. Appetite[Internet].2008 Mar[cited 2017 Jan 27];50(2-3):252-9. [DOI]

25. Haerens L, Vereecken C, Maes L, De Bourdeaudhuij I. Relationship of physical activity and dietary habits with body mass index in the transition from childhood to adolescence: a 4-year longitudinal study. Public Health Nutrition[Internet]. 2010 Oct[cited 2017 Feb 18]; 13(10A):1722-8.[DOI]

26. Fulton JE, Dai $S$, Steffen LM, Grunbaum JA, Shah SM, Labarthe DR. Physical activity, energy intake, sedentary behavior, and adiposity in youth. American Journal of Preventive Medicine[Internet]. 2009 Jul[cited 2018 May 8];37(1 Suppl):40-9. [DOI]

27. Erkelenz N, Kobel S, Kettner S, Drenowatz C, Steinacker JM, Group TR, et al. Parental activity as influence on children's bMl percentiles and physical activity. Journal of Sports Science and Medicine[Internet]. 2014 [cited 2016 Oct 18];13(3):645-50. [PMID]

28. Maffeis C, Talamini G, Tatò L. Influence of diet, physical activity and parents' obesity on children's 
adiposity: a four-year longitudinal study. International Journal of Obesity[Internet]. $1998 \mathrm{Jul}$ 30[cited 2017 Jan 15];22:758-64. [DOI]

29. Fisher JO, Birch LL. Restricting access to palatable foods affects children's behavioral response, food selection, and intake.The American Journal of Clinical Nutrition[Internet]. 1999 Jun 1 [cited 2017 Jan 11].69(6):1264-72. [DOI]

30. Faith MS, Scanlon KS, Birch LL, Francis LA, Sherry B. Parent-child feeding strategies and their relationships to child eating and weight status. Obesity[Internet]. 2004 Nov [cited 2017 Feb 8];12(11):1711-22. [DOI]

31. Shan $X$. Influence of Parents' Child-feeding Practices on Child's Weight Status among Chinese Adolescents in Beijing, China[PhD thesis]. Carbondale IL: Graduate school Southern Illinois University,Department of Health Education and Recreation [Internet];2010. 189p. [Full Text]

32. Patrick H, Nicklas TA, Hughes SO, Morales M. The benefits of authoritative feeding style: caregiver feeding styles and children's food consumption patterns. Appetite[Internet]. 2005 Apr[cited 2017 Jan 10];44(2):243-9. [Full Text]

33. Kremers SPJ, Brug J, de Vries $H$, Engels RCME. Parenting style and adolescent fruit consumption. Appetite [Internet]. 2003 Aug [cited 2017 May 1];41(1):43-50. [Full Text]

34. Li L, Law C, Conte R Lo, Power C. Intergenerational influences on childhood body mass index: the effect of parental body mass index trajectories. American Journal of Clinical Nutrition [Internet]. 2009 Feb 1[cited 2016 Jun 3];89(2):551-7. [DOI]

35. Davis MM, McGonagle K, Schoeni RF, Stafford F. Grandparental and parental obesity influences on childhood overweight: implications for primary care practice. Journal of American Board of Family Medicine [Internet]. 2008 Dec [cited 2015 Dec 8];21(6):549-54. [DOI]

36. James W. World Health Organization recognition of the global obesity epidemic. International Journal of Obesity[Internet].2008 [cited 2016 Jan 20]; 32: 120-6. [DOI]

37. Obesity Update 2017 [Internet]. Paris: Organization for Economic Co-operation and Development; 2018[cited 2018 May 17]. [Full Text]

38. Health Survey for England, 2016 [Internet]. Leeds(GB): National Health Services Digital. 2017 Dec 13[cited 2018 May 16]. [Website]

39. Overweight and obesity: An overview [Internet]. Bruce(AU): Australian Institute of Health and Welfare; 2018[updated 2018 Jan 17;cited 2018 May 17]. [Website]
40. Jiang $Y, X u$ Y, Bi Y, Wang L, Zhang $M$, Zhou M, et al. Prevalence and trends in overweight and obesity among Chinese adults in 2004-10: data from three nationwide surveys in China. The Lancet. 2015;386(S77). [DOI]

41. The GBD 2015 Obesity Collaborators. Health effects of overweight and obesity in 195 countries over 25 years. New England Journal of Medicine[Internet]. 2017 Jul[cited 2018 Feb 20];6;377(1):13-27. [DOI]

42. National Family Health Survey 4, 2015-16[Internet]. Mumbai: International Institute for Population Sciences(IN), ICF International; 2017[cited 2018 Mar 11]. Chapter 10: nutrition and anaemia;p.300-32. [Website]

43. National Institute of Population Studies, ICF International. Pakistan Demographic and Health Survey 2012-13 [Internet]. Islamabad,Calverton(MD): International Institute for Population Sciences(PK),ICF International; 2013[cited 2016 Jan 25]. Chapter 1:Nutrition of children and women;pg.181-2. [Full Text]

44. Ogden CL, CarrollMD, FryarCD, Flegal KM. Prevalence of obesity among adults and youth: United States, 2011-2014 [Internet]. Hyattsville(MD):National Center for Health Statistics. 2015 [cited 2017 Oct 11]. [Website]

45. Ogden CL, Carroll MD, Kit BK, Flegal KM. Prevalence of childhood and adult obesity in the United States, 2011-2012. Journal of American Medical Association[Internet]. 2014 Feb 26 [cited 2016 Jan 5];311(8):806-14. [DOI]

46. National Center for Health Statistics. Health, United States, 2013 with special feature on prescription drugs [Internet]. Hyattsville(MD):National Center for Health Statistics. 2014[cited 2017 Jan 15]. [Full Text]

47. United Nations Children Fund, World Health Organization, World Bank. Levels and trends in child malnutrition: key findings of the 2018 edition of the joint child malnutrition estimates [Internet]. United Nations Children Fund, World Health Organization, World Bank; 2018 [cited 2018 May 17]. [Full Text]

48. Cheng TO. Obesity in Chinese children. Journal of the Royal Society of medicine[Internet]. 2004 May[cited 2017 Sep 24];97(5):254. [PMID]

49. Ranjani H, Mehreen TS, Pradeepa R, Anjana RM, Garg R, Anand K, et al. Epidemiology of childhood overweight and obesity in India: A systematic review. Indian Journal of Medical Research[Internet]. 2016 Feb 1 [cited 2018 Feb 25];143(2):160. [DOI]

50. Sultana S, Saleh F, Ali L. Childhood obesity in primary school children of middle and upper-middle income group in the capital city of Bangladesh. Food and 
Nutrition Sciences[Internet]. 2015[cited 2017 Dec 18];06(13):1185-92. [DOI]

51. Ahmed J, Laghari A, Naseer M, Mehraj V. Prevalence of and factors associated with obesity among Pakistani schoolchildren: a school-based, crosssectional study. Eastern Mediterranean Health Journal[Internet]. 2013 Mar[cited 2017 Jan 14];19 (3) , 242-7. [Full Text]

52. Bhandari TR, Chhetri M. Nutritional status of under five year children and factors associated in Kapilvastu district, Nepal. Journal of Nutritional Health and Food Science[Internet]. 2013 Dec[cited 2016 Sep 2]; 1(1):6. [DOI]

53. Gaurav K, Poudel IS, Bhattarai S, Pradhan PMS, Pokharel PK. Malnutrition status among under-5 children in a hill community of Nepal. Kathmandu University Medical Journal[Internet]. 2014 [cited 2017 April 18];12(48):264-8. [Full Text]

54. Ghosh A, Adhikari P, Chowdhury SD, Ghosh T. Prevalence of undernutrition in Nepalese children. Annals of Human Biology [Internet]. 2009 Jan [cited 2015 Sep 28];36(1):38-45. [Full Text]

55. Nepal and the millenium development goals, final status report 2000-2015[Internet]. Kathmandu: National Planning Commission(NP), Government of Nepal;2016[cited 2017 Jul18]. [Website]

56. Acharya B, Chauhan HS, Thapa SB, Kaphle HP, Malla D. Prevalence and socio-demographic factors associated with overweight and obesity among adolescents in Kaski district, Nepal. Ind J Community Health[Internet]. 2014 [cited $2016 \mathrm{Nov}$ 5]; 26(6):118-122. [Full Text]

57. Koirala M, Khatri RB, Khanal V, Amatya A. Prevalence and factors associated with childhood overweight/ obesity of private school children in Nepal. Obesity Research \& Clinical Practice [Internet]. 2015 May [cited 2017 Feb 4];9(3):220-7.[DOI]

58. Raut BK, Jha MK, Baidya D, Shrestha HD, Sapkota S, AryalM et. al. Determination of risk factors associated with childhood obesity and the correlation with adult obesity- a random cross sectional study from Nepal. American Journal of Health Research [Internet].2014 [cited 2017 Mar 9];2(4):134. [DOI]

59. Sah VK, Giri A, Acharya R. Prevalence of overweight, obesity and its associated risk factors among school children aged 6-16 years of Biratnagar. Journal of Nobel Medical College[Internet]. 2016 Dec 26 [cited 2017 Jul 5];5(2):22-5. [Full Text]
60. Amatya B, Shrestha N. Prevalence of Malnutrition in a Rural Residential Sanskrit School in Baglung, Nepal. Journal of Nepal Medical Association[Internet]. 2017[cited 2017 Jul 8]; 56(205):153-7. [Full Text]

61. Kharel S. Associated risk factors and prevalence of overweight among pre-school children of Bhaktapur, Nepal, International Annals of Medicine[Internet]. 2017 Apr [cited 2017 Oct 5];1(3). [DOI]

62. Lobstein T, Baur L, Uauy R. Obesity in children and young people: a crisis in public health. Obesity Reviews [Internet]. 2004 [cited 2016 Oct 9];5(Supp1):4-85. [Full Text]

63. Al-Shookri A, Al-Shukaily L, Hassan F, Al-Sheraji S, Al-Tobi S. Effect of mothers nutritional knowledge and attitudes on Omani children's dietary intake. Oman Medical Journal[Internet]. 2011[cited 2018 Apr 20];26(4):253-7. [DOI]

64. Barriuso L, Miqueleiz E, Albaladejo R, Villanueva $R$, Santos JM, Regidor E. Socioeconomic position and childhood-adolescent weight status in rich countries: a systematic review, 1990-2013. BMC Pediatrics [Internet]. 2015 Dec [cited 2015 Oct 27];15(1). [DOI]

65. Factsheets: Physical activity[Internet].Geneva: World Health Organization; 2018[updated 2018 Feb 16; cited 2018 July 20]. [Website]

66. Kelder SH, Perry CL, Klepp KI, Lytle LL. Longitudinal tracking of adolescent smoking, physical activity, and food choice behaviors. American Journal of Public Health[Internet]. 1994 Jul[cited 2018 Jun 17];84(7):1121-6. [PMCID]

67. Brown R, Ogden J. Children's eating attitudes and behaviour: a study of the modelling and control theories of parental influence. Health Education Research[Internet]. 2004 Jun 1[cited 2017 Jun 19];19(3):261-71. [DOI]

68. Laitinen J, Power C, Järvelin MR. Family social class, maternal body mass index, childhood body mass index, and age at menarche as predictors of adult obesity. American Journal of Clinical Nutrition[Internet].2001[cited 2016 Aug 20];74(3):287-94. [DOI]

69. Jones AR, Parkinson KN, Drewett RF, Hyland RM, Pearce MS, Adamson AJ. Parental perceptions of weight status in children: the Gateshead millennium study. International Journal of Obesity[Internet]. 2011 Jul [cited 2016 Sep 9];35(7):953-62. [DOI] 